\title{
EFFECTS OF LOCAL BUCKLING OF COMPONENT PLATES ON THE STRENGTH OF WELDED STEEL MEMBERS
}

\author{
By Akio HASEGAWA*, Mohamed MAUROOF** and Fumio NISHINO***
}

\begin{abstract}
A constitutive equation for buckled plate components is established based on the effective width concept to account not only for the reduction of effective area but also for a sudden drop of axial stiffness at the instant of buckling. Based on this, the updated Lagrangian FEM analysis is performed to predict the interactive column and beam-column behavior of built-up steel sections with local buckling, and is proved accurate by the comparison with the tests. The existing interactive design formulae have been examined through the analysis, and some practical implications are made.

Keywords: local buckling, effective width, constitutive equation, interactive behavior, FEM analysis, steel structural design
\end{abstract}

\section{INTRODUCTION}

In conventional design of steel members, the occurrence of local buckling of component plates is avoided by specifying the maximum values of plate width-thickness ratios. However, it is widely believed that allowing of local buckling of component plates may lead to more economical design. Due to this reason, several design specifications have incorporated design provisions allowing local buckling of component plates to occur. The American Institute of Steel Construction ${ }^{1)}$ (AISC) and the Japan Road Association ${ }^{2)}$ (JRA) have given certain interactive formulae, to take account of component plate buckling on the overall buckling of members. However, these interactive formulae seem to be based on intuition, without much emphasis on theoretical or experimental basis. Therefore, the validity of these design provisions must be examined. Moreover, as far as these design formulae are concerned, an optimization study ${ }^{3)}$ has recently indicated that allowing of local buckling of component plates does not necessarily give economical designs, particularly for members of ordinary civil engineering structures. Those combined facts have brought about a strong need for a through investigation regarding the interactive behavior. Besides the researches conducted recently concerning the plate and column behaviors with a particular attention to their interactive steel column strength with local buckling both theoretically) ${ }^{4)}$ and experimentally ${ }^{8)}$, a simplified analysis ${ }^{9}$ based on the Perry-Robertson formula and the effective width concept has recently shown that both AISC and JRA design provisions give conservative design values, specially in the range of column slenderness of normal civil engineering structures. However, this simplified analysis is based

* Member of JSCE, Dr. Eng., Associate Professor, Division of Structural Engineering and Construction, Asian Institute of Technology (G. P. O. Box 2754, Bangkok 10501, Thailand) on leave from Univ. of Tokyo.

** Dr. Eng., Lecturer, Department of Civil Engineering, University of Peradenia (Peradenia, Sri Lanka), formerly Graduate Student, Department of Civil Engineering, Univ. of Tokyo (Bunkyo-ku, Tokyo).

*** Member of JSCE, Ph. D., Professor, Department of Civil Engineering, Univ. of Tokyo (Bunkyo-ku, Tokyo). 
simply on elastic beam-column theory, which involves a considerable degree of approximation.

In this paper, an inelastic finite displacement analysis of steel members with local buckling of component plates is carried out using the finite element technique. Firstly, the component plate behavior is modelled using the von-Kármán effective width concept, with proper accommodation for the effects of initial imperfections and welding residual stresses. A new constitutive equation in the form of the incremental stress-strain relationship of a plate supported along its edges is developed, incorporating the effects of local buckling and inelasticity, and is compared with the available analytical results ${ }^{10)}$. Secondly, nonlinear finite element analysis is performed, based on the newly developed constitutive equation, in accordance with the available experimental results ${ }^{11)}$ of centrally and eccentrically loaded columns. The validity of present FEM analysis is checked by comparing with those experimental results. In all the above cases, the present formulation gives reasonable agreement with available results. Having confirmed the validity of the present formulation to represent the real steel column behavior with component plate buckling, computations are also made in conjunction with the design curves of columns, and are compared with the available design provisions. Further computations and comparisons are carried out for members under bending and compression. Based on these comparisons, certain suggestions are made to improve available design curves.

\section{CONSTITUTIVE EQUATION OF PLATE WITH BUCKLING}

Most of the available finite displacement plate solutions are restricted for certain types of boundary conditions or loads and involve a considerable amount of numerical computations even to analyze a single plate component. Therefore, to use these methods to analyze a general thin-walled member consisting of several plate elements will be generally expensive and complicated ${ }^{4)}$ (7). Most specifications use the well-known effective width formulae, based on the observed experimental ultimate strength of plate components. Although some efforts have been devoted in the past ${ }^{12) .13)}$, to improve the effective width formulae for better accuracy, however, there has been little attempt to establish the constituting equation for the post-buckling range of plates, and then trace the load-displacement behavior in the sub-ultimate range, incorporating the reduced stiffness incurred by plate buckling. The constitutive equation of interest is developed here in an explicit way with the use of the effective width concept available for sub-ultimate range, demonstrating a sudden decrease of stiffness at the instant of buckling.

\section{(1) Proposed model of plate behavior}

The load $P$ carried by a purely compressed rectangular simply supported plate component in the sub-ultimate post-buckling range can be given as

$$
P=A \sigma_{a v}=A_{e} \sigma_{\max } \text { where, } A_{e}=b_{e} t
$$

in which $A=b t$ is the original cross sectional area of plate component with width $b$ and thickness $t, \sigma_{a v}$ is the average stress for the total width of the plate, $A_{e}$ is the effective cross sectional area given by the effective width $b_{e}$ multiplied by plate thickness $t$ for the stress level of $\sigma_{\max }$, and $\sigma_{\max }$ is the maximum stress which occurs along the supported edge, as shown in Fig. 1. In the post-buckling sub-ultimate range, the effective width for the plate can be expressed in a general form as ${ }^{9}$

$$
b_{e}=F t \sqrt{\frac{E}{\sigma_{\max }}}
$$

in which $E$ is the modulus of elasticity, and $F$ is given as

$$
F=C \pi \sqrt{\frac{k}{12\left[1-\nu^{2}\right]}}
$$

where $k$ is the buckling coefficient of plate, $\nu$ is Poisson's ratio and $C(<1)$ is the reduction factor to reflect the initial imperfections present in actual steel plates.

Since there is no out-of-plane displacement along the supported edge, the strain increment of the plate edge is related to the increment of the maximum stress by the constitutive equation as 


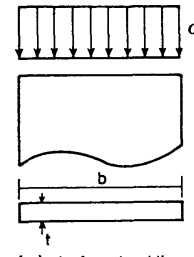

(a) before buckling

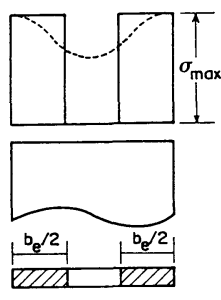

(b) after buckling

Fig. 1 A Plate under Uniform Compression.

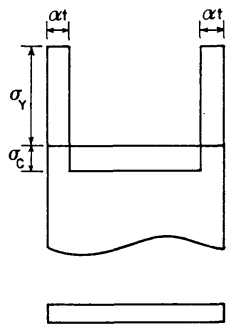

(a) Residual Stress Distribution

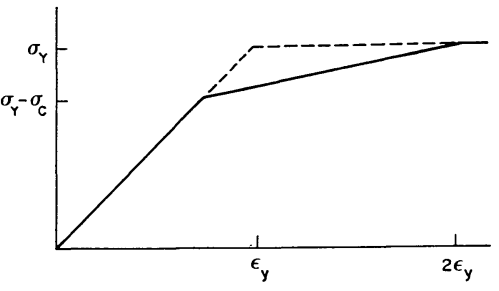

(b) Stress Strain Curve
Fig. 2 Residual Stresses and Resulting Stress-Strain Curve.

$d \sigma_{\max }=E_{t} d \varepsilon$

in which $E_{t}$ is the tangent modulus corresponding to plate without local buckling but with imperfections such as residual stresses and initial out-of-flatness. It should be noted that the initial tangent modulus $E$ is used in Eq. (3), since the calculation of $C$ was based on this value of $E$, while, for the incremental stress strain relationship of Eq. (5), tangent modulus $E_{t}$ is used, which depends on the stress level of the plate component.

Taking the incremental form of Eq. (1) leads to

$d P=\sigma_{\max } d A_{e}+A_{e} d \sigma_{\max }$

Note that, before buckling with the uniform stress $\sigma$, Eq. (6) is reduced in a familiar form as

$$
d P=A d \sigma=E_{t} A d \varepsilon \text { or } d \sigma=\frac{d P}{A}=E_{t} d \varepsilon
$$

because no differentiation is needed for $A$. Knowing from Eqs. (2) and (3) that

$$
A_{e}=F t^{2} \sqrt{\frac{E}{\sigma_{\max }}}
$$

differentiation of Eq. ( 8 ) with respect to $\sigma_{\max }$, and then substituting the obtained $d A_{e}$ and $A_{e}$ of Eq. ( 8 ) into Eq. (6) lead to

$$
d P=\frac{1}{2} F t^{2} \sqrt{\frac{E}{\sigma_{\max }}} d \sigma_{\max }
$$

Rewriting Eq. (9) in terms of $A_{e}$ and $d \varepsilon$ with the use of Eqs. (5) and (8) finally yields

$$
d P=\frac{1}{2} E_{t} A_{e} d \varepsilon \text { or } d \sigma=\frac{d P}{A}=\frac{1}{2} E_{t} \frac{A_{e}}{A} d \varepsilon
$$

Eq. (10) implies in connection with Eq. ( 7 ) for the plate before buckling that the stiffness of the plate should be multiplied by the factor of half in the post buckling range. Therefore, at the instant of buckling load, the slope of the stress-strain curve of a plate reduces suddenly by half. Beyond the buckling load, the slope variation is gradual depending on the change of the effective width as well as tangent modulus $E_{t}$. It is noted that this phenomenon has been observed in some classical analytical solutions of elastic perfect plates $^{14) .15)}$ as well, but has not drawn much attention in recent developments. It is remembered for actual imperfect plates that the slope variation of stress-strain curves is gradual from the beginning without showing such a sudden drop of stiffness, but seems to be very close to the solution of perfectly flat plates.

\section{(2) Evaluation of modelled plate behavior}

Here only the effect of residual stresses on $E_{t}$ is considered and the effect of initial imperfections is neglected. In this study, the welding residual stress pattern is assumed as shown in Fig. 2(a). Residual stress of high tension equivalent to yield stress of material is assumed to exist with a narrow band width $\alpha$-times the thickness of the plate, along the weld line. In the other regions, uniform compressive residual stress is assumed, which is in equilibrium with tension band. It should be noted here that the residual stress is assumed in terms of the width of the tension strip, instead of generally accepted method of 
constant compressive stress. This is because in stocky plates the effect of residual stress should be reflected more than in very slender plates. This condition can be achieved through the present assumption. Based on the assumed residual stress distribution of Fig. 2(a), the stress-strain relationship for the plates without local buckling is approximated to be trilinear in the form as shown in Fig. 2(b), where $\sigma_{c}$ is equal to compressive residual stress. Ultimate condition is assumed to occur when the total strain is twice the yield strain. The tangent modulus $E_{t}$ from Fig. 2(b) is used here in modelling the plate behavior.

Considered to compare the modelled plate behavior is the analytical result obtained using the perturbation method ${ }^{10)}$ for a simply supported plate under uniform compression, based on the assumed initial deflection and the residual stress distribution, which govern dominantly the ultimate strength and load-deflection curves of the plate. On the other hand, the ultimate strength of the present formulation is governed by the stress-strain relationship of the plate component as given in Eq. (10), and thus is dependent on the factor $C$ appeared in Eq. (4). Therefore, to model the available analytical results, parameter $C$ should be chosen such that the ultimate strength of plates in both cases be equal, while keeping the residual stresses in both cases the same.

Based on this, the present results are obtained, and the comparison is made in Fig. 3 for plates with width-thickness ratio $30,40,55$ and 80 which correspond to non-dimensionalized plate slenderness $\lambda_{1}$ of $0.554,0.739,1.02$ and 1.48 respectively, for $\sigma_{y}=250 \mathrm{MPa}$ and $E=2.1 \times 10^{5} \mathrm{MPa}$, where $\lambda_{1}$ is given by

$$
\lambda_{1}=\frac{1}{\pi} \sqrt{\frac{\sigma_{y}}{E} \frac{12\left[1-\nu^{2}\right]}{k}} \frac{b}{t}
$$

Observing the comparison, it can be said that the present model gives the nonlinear stress-strain relationship only after the critical stress, while the nonlinearity of

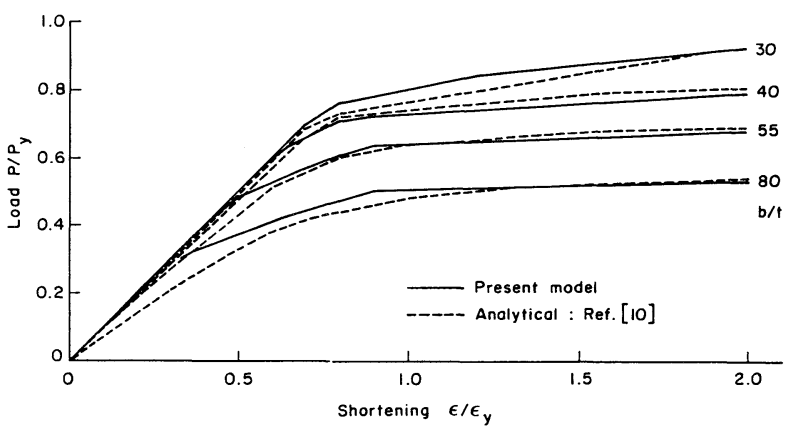

Fig. 3 Comparison of Load-Shortening Curves for Plate Components. the analytical result is gradual from the initial state, which seems more rational in a rigorous sense for plates with imperfection. Due to this reason, the maximum difference between the analytical results and the present model can be observed near the critical state. However, as a whole, the stress-strain curves of analytical results and those of present model seem to give good agreement. It should be noted that, while the analytical results quoted naturally involved some numerical computational work and therefore are rather difficult to apply for the problem of plate assemblage, the proposed model is simply the constitutive equation in an explicit form as given by Eq. (10), incorporating the effective width concept. This seems to contribute very much to the direct incorporation of the effects of local buckling on the overall behavior of column strength.

Although the effective width formula used in Eq. (3) is for a purely compressed simply supported plate, an adequate substitute is available for a plate subject to bending and compression ${ }^{16)}$ and/or for an outstanding flange plate ${ }^{17}$, and can be applied when the beam-column problem of any sectional shape with local buckling is a matter of concern.

\section{NONLINEAR FINITE ELEMENT ANALYSIS}

A plane beam-column element consisting of thin plate components is nonlinear in terms not only of finite displacements but also of the constitutive equation as seen in Eq. (10). Therefore, at each stage in the loading path, the effective width and stiffness coefficient will change for each plate component. Due to this nonlinearity, an incremental finite element formulation based on the updated Lagrangian procedure is employed here for the member analysis. The tangent stiffness matrix comprising the small displacement 
and geometric stiffness matrices is very similar to the normal beam element except that the modified equivalent sectional properties are used instead of the original sectional properties ${ }^{18}$. The modified effective sectional properties are calculated at each point along the loading path using the effective area of plate components based on constitutive Eq. (10), which depends on the stress level of the plate components. With the effective area of each plate element to be modified by a factor $k_{i}^{*}$ and summing over the cross section, the modified effective area of the whole section can be given as

$$
A_{e g}=\sum_{i} k_{i}^{*} A_{e i}
$$

in which

$$
k_{i}^{*}=E_{t i} / E
$$

in the pre-buckling range with $A_{e i}=$ the original area $A_{i}$, and

$$
k_{i}^{*}=E_{t i} / 2 E
$$

in the post buckling range where $A_{e g}$ and $A_{e i}$ stand for the effective area of the whole section and plate component $i$, respectively. The modified first and second moments of inertia are computed in a similar manner, taking into account the reduced stiffness of each plate component as given in Eq. (10).

\section{COMPARISON OF TESTS WITH FEM ANALYSIS}

Although quite recent data are available for the experiments of $\mathrm{H}$ shaped columns ${ }^{8}$, the test data considered here for comparison are from Reference 11) which includes the experimental results of welded built-up columns of SM 58 grade of steel comprising centrally and eccentrically loaded columns as shown in Fig. 4. The specimen designation (see Table 2) starting with character $S$ refers to centrally loaded column having square box section, while $R$ to centrally loaded rectangular box columns (the depth to breadth ratio $d / b$ is kept constant as 0.75$)$. The ER and ES series specimens are loaded at both ends with equal eccentricities of $e=r / 4$ ( $r$ being the radius of gyration about the weak axis of cross section). In each specimen, the figure following the character represents the value of slenderness ratio $L / r$ of the column and the second figure represents the value of flange width-thickness ratio $b / t$. For SM 58 grade steel, measured yield stress $\sigma_{y}=568 \mathrm{MPa}$, Young's modulus $E=213000 \mathrm{MPa}$ and Poisson's ratio $\nu=0.225$ are assumed in the present analysis.

Stub column tests for the column slenderness ratio of 10 have given the value of $C$ in Eq. (4) as 0.737 , which is used in the present FEM analysis to trace the load displacement behavior of columns. In the above experimental study, residual stress measurements were carried out for three sections with plate width-thickness ratios of 29,44 , and 58 . The observed residual stress patterns were very similar to assumed residual stress pattern in Fig. 2. The average value of measured compressive stress is given in Table 1. The tabulated tension strip widths are based on these measured residual stresses, assuming the tensile residual stress to be equal to yield stress. Based on these results, the average value of tension strip is taken as 3.75 times the plate thickness in the present analysis. It is noted here that the variation of observed compressive stress is very large in comparison with the variation of width of the tension strip. This justifies the present assumption to represent the residual stress by the width of the tension strip.
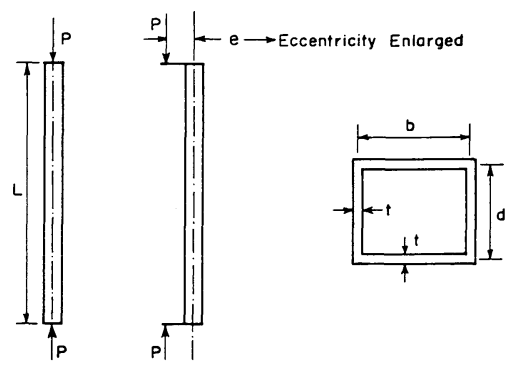

Table 1 Measured Compressive Residual Stress and Computed Tension Strip Width.

\begin{tabular}{|c|c|c|}
\hline$b / t$ & $\sigma_{\mathrm{c}} / \sigma_{\mathrm{y}}$ & $\alpha$ \\
\hline 29 & 0.32 & 3.515 \\
44 & 0.22 & 3.967 \\
58 & 0.15 & 3.782 \\
\hline
\end{tabular}

Fig. 4 Centrally and Eccentrically Loaded Columns. 
Table 2 Comparison of Tests with FEM Analysis.

\begin{tabular}{|c|c|c|c|}
\hline Specimen & $\begin{array}{c}\text { Tests } \\
\sigma_{\mathrm{v}} / \sigma_{\mathrm{y}}\end{array}$ & $\begin{array}{c}\text { Analysis } \\
\sigma_{\mathrm{u}} / \sigma_{\mathrm{y}}\end{array}$ & $\sigma_{\text {exp }} / \sigma_{\text {znt }}$ \\
\hline $\mathrm{R}-40-29$ & 0.798 & 0.795 & 1.004 \\
$\mathrm{R}-40-44$ & 0.644 & 0.619 & 1.040 \\
$\mathrm{R}-40-58$ & 0.498 & 0.479 & 1.039 \\
$\mathrm{R}-65-29$ & 0.619 & 0.570 & 1.086 \\
$\mathrm{R}-65-44$ & 0.521 & 0.470 & 1.108 \\
$\mathrm{R}-65-58$ & 0.441 & 0.372 & 1.185 \\
ER-40-29 & 0.610 & 0.648 & 0.941 \\
ER-40-44 & 0.501 & 0.492 & 1.018 \\
ER-40-58 & 0.391 & 0.394 & 0.992 \\
ER-65-29 & 0.435 & 0.430 & 1.012 \\
ER-65-44 & 0.406 & 0.381 & 1.066 \\
ER-65-58 & 0.312 & 0.317 & 0.984 \\
ES-40-44 & 0.441 & 0.454 & 0.971 \\
ES-40-58 & 0.363 & 0.357 & 1.017 \\
\hline
\end{tabular}

Computations are made both for centrally and eccentrically loaded columns, by dividing the column into ten elements for finite element solutions. For centrally loaded columns, the initial deflection of $L / 1000$ is assumed, which is the maximum allowable value under JRA specification ${ }^{2)}$. The eccentrically loaded columns are assumed to be initially straight. The comparison of the tests and the present analysis for ultimate strengths is given

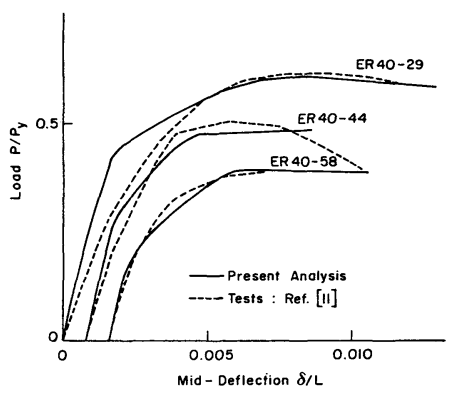

(a)

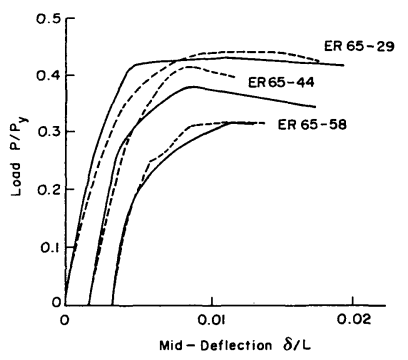

(b)

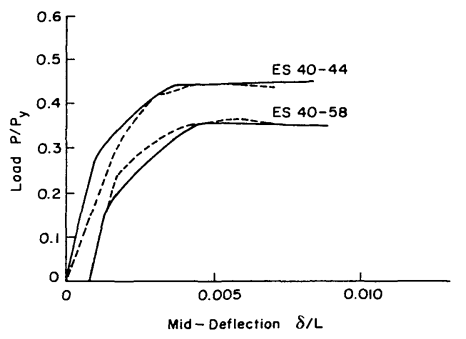

(c)

Fig. 5 Comparison of Load-Deflection Curves of Eccentrically Loaded Columns.

in Table 2. For centrally loaded columns, the present analysis tends to give somewhat conservative results. This may be justified due to the reason that the assumed initial deflection of centrally loaded column in the analysis may not be the representative value of experimental specimens. For eccentrically loaded columns, the present analysis is in good agreement with the tests and falls on either side of them. The analysis by Usami et al. ${ }^{11)}$ gives rather higher value of ultimate strength for members without local buckling (width-thickness ratio of 29), while, in the present analysis, the results are in good agreement. This may be due to the reason that the effect of residual stresses is taken properly into consideration in the present analysis.

The comparisons of load-midheight deflection curves for eccentrically loaded columns are shown in Figs. 5 $(\mathrm{a}-\mathrm{c})$. For most of the members, the experimental initial slopes are smaller than those of the analytical curves. This may be due to the reason that the actual stiffness of plate component is reduced due to the plate imperfection as shown by the exact results of Fig. 3 and the initial imperfection of columns may be in the same direction as the deflection resulting from the load in all the test specimens. The computed load-deflection curves show sharp changes in slope both at the onset of initial local buckling and at the point of yielding for compressive residual stress region. As a whole, however, it can be said that a good agreement between experimental and analytical results can be noted both in pre and post ultimate ranges, even though the effect of strain hardening is not taken into consideration in the present analysis. 


\section{COMPARISON OF FEM ANALYSIS WITH DESIGN FORMULAE}

For the overall strength of columns and beam-columns, the design curve given by $\mathrm{JRA}^{2)}$ is considered in this study. When local buckling of component plate is permitted, the interactive formulae of JRA and $\mathrm{AISC}^{1)}$ are considered for comparison, with the plate strength formulae being in consistent with JRA specification. It should be noted, however, that the appropriate selection of the plate strength depends on whether local buckling stress or ultimate stress of component plate influences more on the interactive column strength. Although the current JRA specification adopts the local buckling stress as a safer approximation, here in this study, only the ultimate stress of component plate is considered for comparison. The explicit expression of the design formulae quoted here are given in a concise form in Reference 9).

\section{(1) Column design}

Three types of sections are considered, namely square box, rectangular box $(d / b=0.75)$ and H-shape section with equal web and flange width and thicknesses. The width of tensile residual stress strip is taken as three times the thickness of the plate, and the value of $C$ in Eq. (4) is taken 0.7, which is consistent with the JRA design formula as explained in Reference 9). The residual stress distribution of the flange of $\mathrm{H}$ section is assumed the same as the half part of Fig. 2(a). The steel is assumed to be with yield stress of $460 \mathrm{MPa}$ and $E=215000 \mathrm{MPa}$ and $\nu=$ 0.24 for all the following computations.

When the JRA or AISC formula is applied in the evaluation of interactive column strength, a single value for the local strength of plate component has to be used. But, in general, a column may have more than one plate component and their respective buckling/ultimate strengths may not be the same. Therefore, selection of proper local strength becomes difficult, and the interactive strength will depend on which plate element is chosen. These difficulties are particularly evident in non-square, rectangular box and $\mathrm{H}$-sections, since the flange and web plates have different plate slenderness. In this study, the minimum strength and the average strength of all the plate components are considered for comparison. Designation $I$ is given for the former case of the minimum strength, while designation II for the latter case of the average strength both in JRA and AISC design provisions.

The initial deflections of column are determined in computations such that the present analysis coincides with the overall column curve, when there is no local buckling. These are considered as the equivalent initial deflections as demonstrated in Reference 9). For square box, rectangular box and $\mathrm{H}$-shaped sections, the value of equivalent initial deflections are obtained as $0.003,0.003$ and 0.004 , respectively. Using these values of equiva-

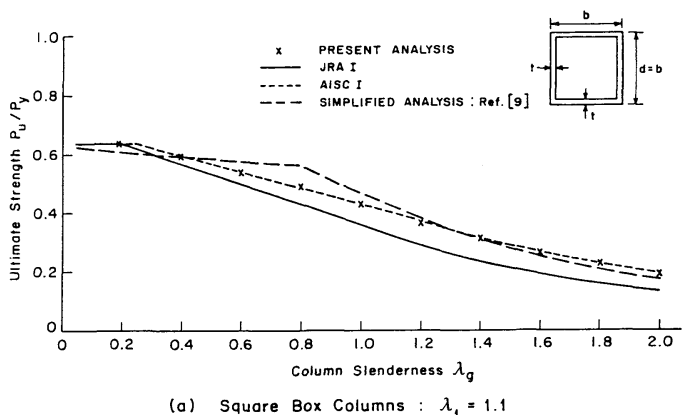

(a) Square Box Columns : $\lambda_{1}=1.1$

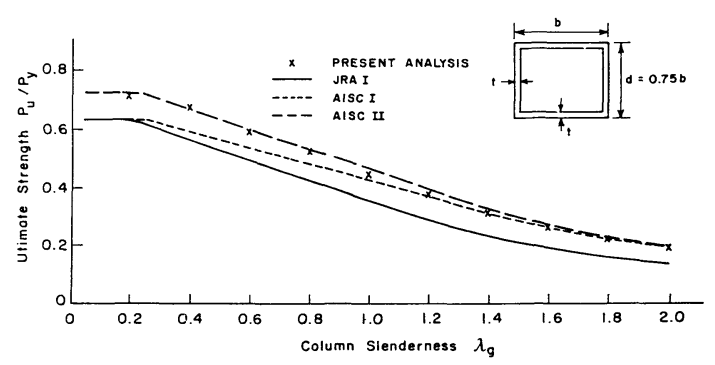

(b) Rectongular Box Columns : $\lambda_{1}=1.1$

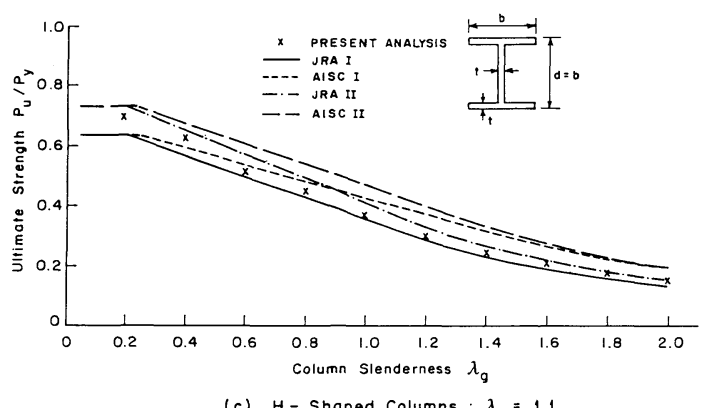

(c) $H$ - Shaped Columns: $\lambda_{1}=1.1$

Fig. 6 Strength Evaluations of Columns with Local Buckling. 
lent initial deflections and permitting the local buckling of component plates to occur, interactive column strengths are computed by the proposed FEM analysis for the columns of interest with different plate slenderness ratios. Typical results are shown in Figs. $6(\mathrm{a}-\mathrm{c})$ for the plate slenderness of $\lambda_{1}=1.1$, where the effect of local buckling are rather remarkable. Symbol $\lambda_{g}$ in figures is the column slenderness as given by

$$
\lambda_{g}=\frac{1}{\pi} \sqrt{\frac{\sigma_{y}}{E}} \frac{L}{r}
$$

It is seen from the results that selection of the local plate strength, I or II, plays a rather significant role on the interactive strength, and any of the design curves considered does not coincide with the present FEM analysis for all the cross sections of interest. It can only be said that the AISC II curves can predict well the column strength for box shaped sections, while the JRA I seems to be closest of all the curves considered for $\mathrm{H}$-shaped sections. Therefore, it is concluded that none of the existing interactive design formulae even with some modifications does not predict a variety of column behaviour well, and thus some allowance must be admitted in precision for practical applications.

\section{( 2 ) Beam-column design}

When a plane member is subjected to equal end moment and compression, the JRA specification stipulates the following inequalities as

$$
\frac{\sigma_{a}}{\sigma_{u a}}+\frac{\sigma_{m}}{\sigma_{u m}\left[1-\sigma_{a} / \sigma_{c r}\right]} \leq 1
$$

and

$$
\sigma_{a}+\frac{\sigma_{m}}{\left[1-\sigma_{a} / \sigma_{c r}\right]} \leq \sigma_{1}
$$

in which $\sigma_{a}$ is the stress due to axial compression $P, \sigma_{u a}$ is the centrally loaded column strength, $\sigma_{c r}$ is the elastic critical stress of column, $\sigma_{m}$ is the compressive stress due to the applied bending moment $M, \sigma_{u m}$ is the ultimate bending compressive stress without consideration of local buckling, and $\sigma_{1}$ is the local plate strength. The value of $\sigma_{u a}$ can be determined by any of the centrally loaded column interaction formulae. The ultimate bending compressive stress $\sigma_{u m}$ can be taken as $\sigma_{y}$ for all the cases since no lateral buckling is considered in this study. The bending compressive stress $\sigma_{m}$, denoted as $\sigma_{m 1}$ for later comparison, is determined using the original sectional properties without any consideration of local buckling as

$$
\sigma_{m 1}=\frac{M}{I} s
$$

where $I$ is the original moment of inertia of the section and $s$ is the depth of centroidal axis from compression flange.

For the purpose of comparison to find a hint for the improvement of the design procedure, the following modifications are suggested. If bending moment $M$ is applied in addition to compression, the compressive flange will buckle locally while tension flange will remain fully effective. Assuming compression flange to reach yield stress at ultimate stage, the bending stress, denoted as $\sigma_{m 2}$ for this modified case, can be evaluated as

$$
\sigma_{m 2}=\frac{M}{I_{e}} s_{e}
$$

in which $I_{e}$ and $s_{e}$ are defined for the effective cross section in a similar way as in Eq. (16). Further, only Eq. $(15 \cdot a)$ is to be considered and Eq. $(15 \cdot b)$ is omitted in the modified version, making only one inequality to be satisfied. In general, neither $\mathrm{Eq}$. (16) nor Eq. (17) gives the actual compressive stress. The actual value of $\sigma_{m}$ may be calculated by some iterative procedure. The above two formulae simply give the special cases only.

Utilizing Eqs. (15-17), the following combinations of design curves are considered for the comparison of the present FEM analysis : (a) the bending compressive stress due to the applied bending moment is 
calculated by Eq. (16), and the column strength $\sigma_{u a}$ is calculated from JRA $\mathrm{I}$, which is termed as JRA, (b) the former is calculated by Eq. (16), and the latter from AISC I termed as AISC, (c) the former calculated by Eq. (17), and the latter from JRA II, termed as modified JRA and (d) the former calculated by $\mathrm{Eq}$. (17), and the latter from AISC II, termed as modified AISC.

The nonlinear FEM analysis is performed for members subjected to equal end moment and compression. Ultimate strengths are obtained from the computed load-deflection relations for various ratios of applied bending moment and axial compression. The same assumptions as in the column design are introduced for the material and cross sectional properties, the values of equivalent initial deflections, and the residual stress distributions. Computations are made for square box, rectangular box and $\mathrm{H}$-shaped columns for various column and plate slenderness. Typical results are shown in Figs. $7(\mathrm{a}-\mathrm{c})$. It is noted that the modified AISC gives very good agreement with the analysis for box shaped sections, while the modified JRA seems to be very close to the analysis for $\mathrm{H}$-shaped sections. It should be remembered, however, that considerable differences exist among the analysis and a variety of the design curves, as seen in the column case. It is worth while to mention that one can not avoid this sort of discrepancies for the design formulae of any kind which are intended to predict the very complicated real behavior of

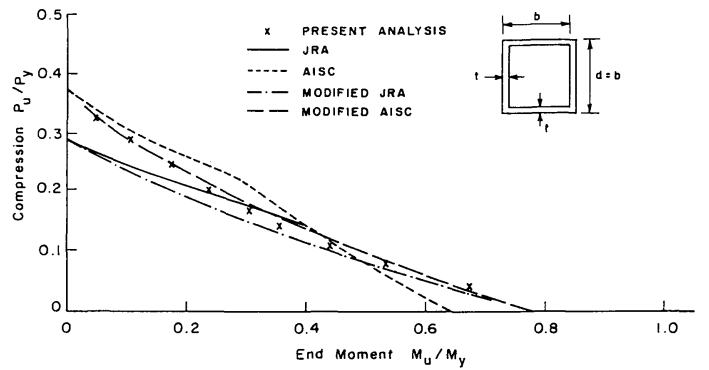

(a) Square Box Columns: $\lambda_{g}=1.2, \lambda_{1}=1.1$

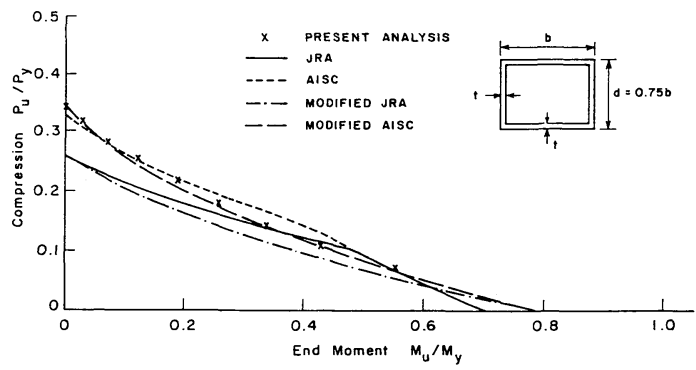

(b) Rectangular Box Columns: $\lambda_{g}=1.4, \lambda_{1}=1.0$

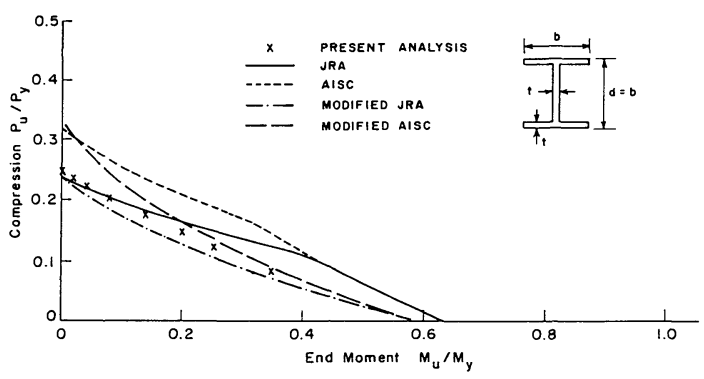

(c) $H$ - Shaped Columns: $\lambda_{g}=1.4, \lambda_{1}=1.1$

Fig. 7 Strength Evaluations of Beam-Columns with Local Buckling. structural components.

\section{CONCLUDING REMARKS}

In order to incorporate the effects of local buckling of component plates into the nonlinear FEM analysis for welded steel members, an appropriate constitutive equation has been established by using the effective width concept of buckled plates. The proposed constitutive equation for buckled plates accounts not only for the reduction of effective area but also for a sudden drop of axial stiffness at the instant of buckling, as given in a simple and explicit form by Eq. (10). The former is rather familiar, but the latter may not have been recognized well, and should be paid more attention to the effects of local buckling. The constitutive equation established has been proved to agree well with the rather complicated nonlinear analysis of the independent plate behavior available in literature.

Using the proposed constitutive equation, the updated Lagrangian FEM analysis incorporating the material and geometrical nonlinearity has been developed and performed in order to examine the interactive column and beam-column behaviors of build-up steel sections. The ultimate strengths as well as the load-deflection curves have been obtained through the analysis, and those have been proved to predict well the experimental results available in literature. The current interactive design formulae given in the AISC 
and JRA specifications have been reviewed, including some modifications for the improvements, and then examined and compared with the present FEM analysis which has been assured for precision from the comparison with the experiments. The results indicate that considerable differences exist among the analysis and a variety of the design curves both in the columns and the beam-columns. None of the existing interactive design formulae even with some modifications does not predict a variety of the column behavior well, and thus some allowance must be admitted in precision for practical applications. It is worth while to mention, however, that one can not avoid this sort of discrepancies for the design formulae of any kind which are intended to predict the very complicated real behavior of structural components.

ACKNOWLEDGEMENT : This study is supported in part by the Grant-in-Aid for Scientific Research from the Japanese Ministry of Education, Science and Culture. Thanks are also due to Mr. Prakash Shrestha, Research Associate at the Asian Institute of Technology, to finalize the preparation of the manuscript.

\section{REFERENCES}

1) AISC : Specification for the Design, Fabrication and Erection of Structural Steel for Buildings, American Institute of Steel Construction, Nov., 1978.

2) JRA : Specification for the Design of Highway Bridges, Part 2, Steel Bridges, Japan Road Association, Feb., 1980.

3) Hasegawa, A., Abo, H. , Mauroof, M. and Nishino, F. : Optimum Cross Sectional Shapes of Steel Compression Members, Structural Eng. /Earthquake Eng., Vol. 2, No. 1, pp.97s 105s, April, 1985, Japan Society of Civil Engineers (Proc. JSCE No. $356 /$ I -3)

4) Usami, T., Tsuchiya, N. and Fukumoto, Y. : Theoretical Study on the Interactive Buckling Behavior of Steel Compression Members, Proc. JSCE, Vol.362/I -4, Oct., 1985 (in Japanese).

5) Usami, T., Tsuchiya, N., Otani, Y. and Fukumoto, Y. : Elastic-Plastic Finite Displacement Analysis of Plate-Assembled Column Segments, Proc. JSCE, Vol.362/I-4, Oct., 1985 (in Japanese).

6) Nakai, H. , Kitada, T. and Miki, T. : Interaction Curve of Thin-Walled Box Stub-Column subjected to Compression and Bending for applying to Overall Buckling Analysis of Columns, Structural Eng. /Earthquake Eng., Vol. 2, No. 2, pp. 311s 319s, Oct., 1985. Japan Society of Civil Engineers (Proc. JSCE No. 362/I-4).

7) Yamao, T. and Sakimoto, T. : Nonlinear Analysis of Thin-Walled Structures by a Coupled Finite Element Method, Structural Eng. /Earthquake Eng. , Vol. 3, No. 2, pp. 225s 234s, Oct., 1986, Japan Society of Civil Engineers (Proc. JSCE No. 374/I $-6)$.

8) Yamao, T. and Sakimoto, T. : An Experimental Study on the Interaction Buckling of Thin-Walled H-Section Columns, Proc. JSCE No. 386/I-4, pp. 383 390, April, 1987 (in Japanese).

9) Hasegawa, A. . Abo, H., Mauroof, M. and Nishino, F. : A Simplified Analysis and Optimality on the Steel Column Behavior with Local Buckling, Structural Eng. /Earthquake Eng., Vol. 3, No.2, Oct., 1986, pp. 363s 372s, Japan Society of Civil Engineers (Proc. JSCE No.374/I-6).

10) Bradfield, C. D. and Stonor, R. W. : Simple Collapse Analysis of Plates in Compression, Journal of Structural Engineering, Vol. 110. No. 12, pp. 2976 2993, Dec., 1984, American Society of Civil Engineers.

11) Usami, T. and Fukumoto, Y. : Welded Box Compression Members, Journal of Structural Engineering, Vol. 110, No. 10, pp. 2457 2468, Oct., 1984. American Society of Civil Engineers.

12) Johnston, B. G. : Guide to Stability Design Criteria for Metal Structures, 3 rd Ed., John Wiley and Sons, New York, N. Y., 1976.

13) Mullingan, G. P. and Pekoz, T. : Locally Buckled Thin Walled Columns, Journal of Structural Engineering, Vol. 110, No. 11, pp. 2635 2654. Nov., 1984, American Society of Civil Engineers.

14) Marquerre, K. and Trefftz, E. : Zeitung fur Ang. Math. a. Mech, Vol. 17, p. 85, 1937.

15) Yamaki, N. : Post Buckling Behavior of Rectangular Plates, Journal of Applied Mechanics, 26, p. $407,1956$.

16) Usami, T. : Post Buckling of Plates in Compression and Bending. Journal of Structural Division, Proc. of the ASCE, Vol. 108, No. ST3, pp. 591 609. Mar., 1982.

17) De Wolf, J. T. . Pekoz, T. and Winter, G. : Local and Overall Buckling of Cold Formed Members, Journal of the Structure Division, Proc. of the ASCE, Vol. 100, No. ST10, pp. 2017 2036. Oct., 1974.

18) Mauroof, A. L. M. : Effects of Local Buckling of Component Plates on the Strength of Thin-Walled Steel Members and Their Systems, Dr. Eng. Thesis, Univ. of Tokyo, Sept. 1986. 